\title{
Outcome Assessment of Perinatal Asphyxia in Children
}

\author{
Dr. S. M. Quamrul Hassan ${ }^{1 *}$, Dr. Jannatul Ferdous², Dr. Mohammad Mostafizur Rahman ${ }^{3}$, Dr. Jayanta Kumer Podder ${ }^{4}$
}

\author{
${ }^{1}$ Assistant Professor, Department of Pediatrics, Shaheed M Monsur Ali Medical College, Sirajganj, Bangladesh \\ ${ }^{2}$ Associate Professor, Department of Gynae \& Obstetric, Ashiyan Medical College Hospital, Barua, Khilkhet, Dhaka, Bangladesh \\ ${ }^{3}$ Assistant Professor \& Head, Department of Anesthesiology \& ICU, Ashiyan Medical College Hospital, BaruaKhilkhet, Dhaka, Bangladesh \\ ${ }^{4}$ Associate Professor, Department of Cardiology, Jashore Medical College Hospital, Jashore, Bangladesh
}

*Corresponding author: Dr. S. M .Quamrul Hassan

\section{Abstract}

Perinatal Asphyxia (also known as Neonatal Asphyxia or Birth Asphyxia in children) is the medical condition resulting from deprivation of oxygen to a newborn infant that lasts long enough during the birth process to cause physical harm, usually to the brain. Perinatal Asphyxia in children is defined by the World Health Organization "the failure to initiate and sustain breathing at birth." The aim of this study was to assess the outcome of Perinatal Asphyxia in children. There were 204 live birth asphyxia neonates whose were clinically diagnosed admitted in the Department of Pediatrics, Shaheed M. Monsur Ali Medical College \& 250 beded Genaral Hospital, Sirajgonj, Bangladesh during the period from January 2017 to December 2018. Clinical information was collected retrospectively from maternal records (maternal age, gravida, type of delivery, presence of meconium, induced or spontaneous labour, and pregnancy complications). The SCANU records provided additional information about new born infant (birth asphyxia, stages of Perinatal Asphyxia in children, birth weight, sex and subsequent mortality). The outcome of treatment in babies with Perinatal Asphyxia in children showing in (Table-3) Recovery rate in group one (HIE I) was 28(13.78\%), in group two (HIE II) was $150(73.53 \%)$ and in group three (HIE III) was $10(4.9 \%)$ and Death ratio was in group one (HIE I) was $2(0.98 \%)$, in group two (HIE II) was $4(1.96 \%)$ and in group three (HIE III) was $10(4.90 \%)$. The morbidity and mortality in cases of Perinatal Asphyxia in children the highest causes of death in stage 3(HIE III), Preterm with Hyaline membrane disease was $4(25 \%)$ and then the higher causes of death in stage-II was Neonatal sepsis $3(18.75 \%)$. Perinatal Asphyxia in children was one of the commonest causes of admission and mortality in SCANU and others beds. Babies with HIE Stage-III had a very poor prognosis. Perinatal Asphyxia in children combined with other morbidities was associated with a higher mortality. Sepsis is the commonest morbidity in cases of Perinatal Asphyxia in children. Maternal gravida, pregnancy complication with PROM, meconium, APH, emergency caesarean section, preterm and male sex were the risk factors for Perinatal Asphyxia in children.

Keywords: Perinatal Asphyxia, Clinical Outcome, Children.

Copyright @ 2020: This is an open-access article distributed under the terms of the Creative Commons Attribution license which permits unrestricted use, distribution, and reproduction in any medium for non-commercial use (NonCommercial, or CC-BY-NC) provided the original author and source are credited.

\section{INTRODUCTION}

Perinatal Asphyxia (also known as Neonatal Asphyxia or Birth Asphyxia in children) is the medical condition resulting from deprivation of oxygen to a newborn infant that lasts long enough during the birth process to cause physical harm, usually to the brain. Perinatal Asphyxia in children is defined by the World Health Organization "the failure to initiate and sustain breathing at birth [1]." The WHO has estimated that 4 million babies die during the neonatal period every year and $99 \%$ of these deaths occur in lowincome and middle income countries [2]. Three major causes account for over three quarters of these deaths, serious infection (28\%) complication of preterm birth (26\%) and Perinatal Asphyxia in children (23\%) [2]. This estimation implies that Perinatal Asphyxia in children is the cause of around one million neonatal deaths each year. One of the present challenges is the lack of a gold standard for accurately defining Perinatal Asphyxia in children. Because of same reason the incidence of Perinatal Asphyxia in children is difficult to quantify. This is demonstrated by the difference in occurrence according to different studies, where the incidence ranges from 5.4/1000 live births in a Swedish study [3] to 22/100 live hospital births in an Indian study $[4,5]$. The incidence of asphyxia in full term infants varies between 2.9-9.0 cases per thousand in industrial countries. The incidence for Perinatal Asphyxia in children is much higher in developing countries [6]. Hospital based studies in Nepal [7] and South Africa [8] estimated that Perinatal Asphyxia in children accounted for $24 \%$ and $14 \%$ of perinatal mortality respectively. However, the study substantially 
underestimate the burden in rural areas, where early deaths, most of which occur at home, and more likely to be underreported. Asphyxia, a lack of oxygen or an excess of carbon dioxide caused by the interruption in breathing, is the result of the failure of the gas exchange organ. There are many reasons a baby may not be able to take oxygen before, during or just after birth. A mother may have medical conditions that can lower her oxygen levels, there may be problem with the placenta that prevents enough oxygen from circulating to the fetus or the baby may be unable to breath after delivery. In mild HIE, muscle tone may be increased slightly and deep tendon reflexes may be brisk during first few days. Transient behavioral abnormalities such as poor feeding, irritability excessive crying or sleepiness may be observed. In moderately severe HIE, the infant is lethargic with significant hypotonia, and diminished deep tendon reflexes. The Grasping, Moro and Sucking reflexes may be sluggish or absent, seizures may occur within 24 hrs of life. In severe HIE, stupor or coma is typical. The infant may not respond to any physical stimulus. Breathing may be irregular and the infant often requires support. Generalized hypotonia and depressed deep tendon reflexes are common. Pupils may be dilated, fixed or poorly reactive to light, seizures occurs early and may be initially resistance to conventional treatments [9]. The aim of present study was to identify the prevalence of Perinatal Asphyxia in children and of avoidable risk factors for neonatal encephalopathy including mortality due to Perinatal Asphyxia in children. Risk factors for Perinatal Asphyxia in children in hospital based setting in developing countries have been categorized into ante partum, intra-partum and post natal characteristics.

\section{Methodology and Materials}

This was a retrospective study on newborns with the diagnosis of Perinatal Asphyxia in children which was conducted in the Department of Pediatrics, Shaheed M. Monsur Ali Medical College \& 250 beded General Hospital, Sirajgonj, Bangladesh during the period from January 2017 to December 2018. The mentioned hospital were finalized as the study population. A total of 204 consecutive asphyxiated newborn who met the inclusion criteria were enrolled in the study. All newborn babies with a clinical diagnosis of Perinatal Asphyxia in children (newborn with history of delayed cry or APGAR score of less than 7 in 5minutes) were included in the study. The four categorical determinants that were considered as follows: pregnancy complications, use of induction of labour (none, oxytocin, misoprostol or both), type of delivery (normal, caesarean and vaccum) and sex of baby. In addition, five continuous determinants were measured which were as follows: age, number of antenatal (ANC) visits, gestational age, gravida and birth weight. The outcome of Perinatal Asphyxia in children irrespective of mortality in different stage of HIE were also determined.

\section{RESULTS}

Figure-1 shows 114(56\%) male and 90(44\%) female included in our study. In Table-1 shows there have three groups in neonates with Perinatal Asphyxia in children in group one (HIE I) male was $14(12.28 \%)$ and female was $16(17.78)$ total was $30(14.71 \%)$, in group two (HIE II) male was $84(73.68 \%$ ) and female was $70(77.78 \%)$ total was $154(75.49 \%)$ and in group three (HIE III) male was 16(14.04) and female was 4(4.44) total was $20(9.8 \%)$. In Table 2 showing that the distribution of determinants associated factors with Perinatal Asphyxia in children the highest Maternal age(18-35 years) was 160(78.43), in Gestational Age (37-42 weeks) was $156(78.47 \%)$, in Gravida (1-2) was 120(58.82), in Pregnancy Complications Thick meconium was $72(37.25 \%)$, in Induction of Labour not Done was $148(72.54 \%)$, in Mode of Delivery Spontaneous was 106(51.96\%), in Birth weight(2500$3000 \mathrm{~kg}$ ) was $102(50)$ and finally the highest range of participant was male 114(55.88\%). The outcome of treatment in babies with Perinatal Asphyxia in children showing in (Table-3) Recovery rate in group one (HIE I) was 28(13.78\%), in group two (HIE II) was $150(73.53 \%)$ and in group three (HIE III) was $10(4.9 \%)$ and Death ratio was in group one (HIE I) was $2(0.98 \%)$ , in group two (HIE II) was $4(1.96 \%)$ and in group three (HIE III) was $10(4.90 \%)$. The morbidity and mortality in cases of Perinatal Asphyxia in children the highest causes of death in stage 3(HIE III) was Preterm with Hyaline membrane disease was $4(25 \%)$ and then the higher causes of death in stage-II was Neonatal sepsis $3(18.75 \%)$.

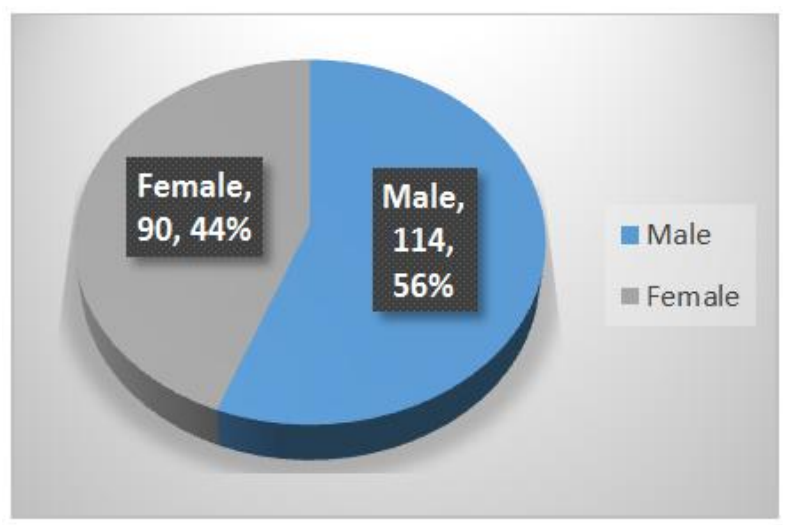

Fig-1: Gender distribution of participants $(n=204)$ 
Table-1: Total number of neonates with Perinatal Asphyxia in children $(n=204)$

\begin{tabular}{|l|l|l|l|l|l|l|l|}
\hline Presentation & Male & \% & & Female & \% & Total & \% \\
\hline HIE I & 14 & 12.28 & & 16 & 17.78 & 30 & 14.71 \\
\hline HIE II & 84 & 73.68 & & 70 & 77.78 & 154 & 75.49 \\
\hline HIE III & 16 & 14.04 & 4 & 4.44 & 20 & 9.8 \\
\hline Grand Total & 114 & & 90 & & 204 & \\
\hline
\end{tabular}

Table-2: Distribution of determinants associated factors with Perinatal Asphyxia in children (n=204)

\begin{tabular}{|c|c|c|c|}
\hline Determinants & Category & Number $(n=204)$ & Percent $(\%)$ \\
\hline \multirow[t]{3}{*}{ Maternal age } & $<18$ years & 24 & 11.76 \\
\hline & $18-35$ years & 160 & 78.43 \\
\hline & $>35$ years & 20 & 9.8 \\
\hline \multirow{3}{*}{ Gestational Age } & $<37$ weeks & 40 & 19.6 \\
\hline & $37-42$ weeks & 156 & 78.47 \\
\hline & $>42$ weeks & 8 & 3.92 \\
\hline \multirow[t]{3}{*}{ Gravida } & $1-2$ & 120 & 58.82 \\
\hline & $2-4$ & 72 & 35.29 \\
\hline & $>4$ & 12 & 5.88 \\
\hline \multirow{9}{*}{ Pregnancy Complications } & Prolapsed & 2 & 0.98 \\
\hline & Heart disease & 6 & 2.94 \\
\hline & Fetal anomaly & 4 & 1.96 \\
\hline & Thick Meconium & 72 & 37.25 \\
\hline & Infection & 24 & 11.76 \\
\hline & Pre-eclampsia & 14 & 6.8 \\
\hline & APH & 30 & 15.68 \\
\hline & Placenta Previa & 12 & 5.88 \\
\hline & Hypertension & 40 & 20.58 \\
\hline \multirow[t]{2}{*}{ Induction of Labour } & Done & 56 & 27.45 \\
\hline & Not Done & 148 & 72.54 \\
\hline \multirow[t]{3}{*}{ Mode of Delivery } & Spontaneous & 106 & 51.96 \\
\hline & Vaccum & 18 & 8.82 \\
\hline & C-Section & 80 & 39.21 \\
\hline \multirow[t]{3}{*}{ Birth weight } & $<2500 \mathrm{~kg}$ & 62 & 30.39 \\
\hline & $2500-3000 \mathrm{~kg}$ & 102 & 50 \\
\hline & $>3000 \mathrm{~kg}$ & 40 & 19.6 \\
\hline \multirow[t]{2}{*}{ Sex } & Male & 114 & 55.88 \\
\hline & Female & 90 & 44.11 \\
\hline
\end{tabular}

Table-3: Showing the outcome of treatment in babies with Perinatal Asphyxia in children (n=204)

\begin{tabular}{|l|l|l|l|l|l|l|}
\hline \multirow{2}{*}{ Stages } & \multicolumn{2}{|l|}{ HIE I (30) } & \multicolumn{2}{l|}{ HIE II (154) } & \multicolumn{2}{l|}{ HIE III (20) } \\
\cline { 2 - 7 } & $\mathbf{N}$ & $\mathbf{\%}$ & $\mathbf{N}$ & \% & N & \% \\
\hline Recovery & 28 & 13.73 & 150 & 73.53 & 10 & 4.90 \\
\hline Death & 2 & 0.98 & 4 & 1.96 & 10 & 4.90 \\
\hline
\end{tabular}

Table-4: Showing morbidity and mortality in cases of Perinatal Asphyxia in children (n=204)

\begin{tabular}{|l|l|l|l|}
\hline HIE stages & Cases & \multicolumn{2}{|c|}{ Mortality } \\
\cline { 3 - 4 } & & $\mathbf{N}$ & $\mathbf{\%}$ \\
\hline \multirow{3}{*}{ HIE I } & Neonatal sepsis with nectrotizing enterocolitis. & 1 & 6.25 \\
\cline { 2 - 4 } & Preterm with hyline membrane disease and neonatal sepsis. & 1 & 6.25 \\
\hline \multirow{3}{*}{ HIE II } & Neonatal sepsis & 2 & 12.5 \\
\cline { 2 - 4 } & Hydrocephalus & 2 & 12.5 \\
\hline \multirow{3}{*}{ HIE III } & Neonatal Sepsis & 3 & 18.75 \\
\cline { 2 - 4 } & NNS with Pneumothorax & 2 & 11.54 \\
\cline { 2 - 4 } & Preterm with Hyaline membrane disease & 4 & 25 \\
\cline { 2 - 4 } & Meconium aspiration syndrome & 1 & 6.25 \\
\hline
\end{tabular}

\section{DISCUSSION}

In spite of major advances in monitoring technology and knowledge of fetal and neonatal pathologies, perinatal asphyxia or more appropriately, hypoxic ischemic encephalopathy (HIE) remain a serious condition, causing significant mortality and long term morbidity. It is a tragedy for a normally developed fetus to sustain cerebral injury during the last hours of intrauterine life and to exist for many years with major handicap. It is seen that for every early neonatal death, three disabled children survive. Perinatal Asphyxia in children and the hypoxic ischemic encephalopathy are one of the common neonatal problems in our country. Our reported incidence of Perinatal Asphyxia in children $(14 \%)$ is almost similar to the incidence in the 
study carried out by Emmaneul Dzodeyan in Africa (40\%) [11]. The incidence of the Perinatal Asphyxia in children in the present study was low in compare to the study conducted by Daga [12] in Kathmandu (27\%) and Azamin Pakistan (48\%) [13]. However the rate is quite high compared with the study by Lodakhi G M in India $(4.18 \%)$ [14]. The asphyxia rate in this study was $26.95 / 1000$ live births. This result is high in number as compared with 5.4/1000 live hospital-born infant in Sweden [3]. This result is similar to $22 / 1000$ live hospital-born infants in a study from India [5] and 12 college hospitals where the incidence was $21.92 \%$ [15]. In this study the largest numbers of babies affected by Perinatal Asphyxia in children were to mothers of 18-35 years $(78.43 \%)$ but this reflected the fact that this aged group represented as the most number of mothers in our obstetric service. So, this study showed that incidence of Perinatal Asphyxia in children was more common between 18-35 years and also shows that an increase or decrease in maternal age was not associated with any risk for Perinatal Asphyxia in children. This result was similar with another study done by Wael Hayel Kreisa and Zeiad Habaheh in Prince Ali Ben Al Hussein Hospital, Jordan [16] in 2005 but different results from the study done by Rachalopantana Kerno et al., at Paltani Hospital, Thailand [17] showed that Perinatal Asphyxia in children was significantly related to maternal age greater than 30years. Antenatal checkups were also studied. Only 16 women $(15.68 \%)$ had no checkup during pregnancy, 62 women $(60.70 \%)$ had regular ANC in selected Hospital and 24 (23.52\%) were having ANC in health post. This study showed less than one-fifth of the women of asphyxiated babies had no ANC checkup during pregnancy. Out of the 102 newborns, 20 babies $(19.60 \%)$ were preterm 78 $(48.47 \%)$ were full term and $4(3.92 \%)$ were post term. The most of the Perinatal Asphyxia in children cases were term babies. This study is different from the statement that post maturity is an important risk factor of Perinatal Asphyxia in children [13, 18]. This study is also different from the statement that prematurity is a significant risk factor for Perinatal Asphyxia in children. When total deliveries were considered, preterm babies were quite less then term babies. So if we consider only the preterm babies, Perinatal Asphyxia in children is common among them. Out of the 102 mothers of asphyxiated babies, 60(58.82\%) were primi gravida, $36(35.29 \%)$ had less than 5 children and 6 mothers $(5.88 \%)$ were having more than 5 children. So these figures show that Perinatal Asphyxia in children was more common in babies delivered by primi gravida. Similar result was shown by Azam M study done in Nishtar Medical College, Multan where the primi gravida was shown to be $47 \%$. But this study didn't show increase incidence of Perinatal Asphyxia in children with grand multipara which is different from the study done by Azam M [13] in Multan where the incidence was $34 \%$. Certain maternal risk factors were assessed by maternal selfreport made during admission. Among 60 mothers who had complications during pregnancy more than half of them had thick meconium stain. So, thick meconium stain liquor showed increase risk factor for Perinatal Asphyxia in children. This result was in contrast with the study done by Anne CC Lee et al., [19] at Southern Nepal which showed meconium stained amniotic fluid had a non-significant greater risk for Perinatal Asphyxia in children (RR: $1.32,95 \% \mathrm{Cl}$ : 0.19 to 2.16 ).This study is comparable with the study done by Lalsclottir $\mathrm{K}$ et al., [20] in Iceland where $50 \%$ of the women of asphyxiated babies had meconium stain amniotic fluid. Among all the women of asphyxiated babies 21 $(20.58 \%)$ had premature rupture of membrane (PROM). Among the women with complicated pregnancy, more than one third had PROM. Study done by Anne CC Lee et al., [19] Southern Nepal and Azam M [13] at Nishtar Hospital, Multan also showed that prolonged rupture of membrane was a significant risk factor for Perinatal Asphyxia in children. Ante partum haemorrhage (APH) and maternal infection was accounted to be $5.68 \%$ and $11.76 \%$ respectively.In this study Perinatal Asphyxia in children was commonly seen in those mothers who had no induction of labour than in those who had induction of labour. Only $28(27.45 \%)$ mothers of asphyxiated babies had induction of labour. The finding in this study did agree with the finding at Pattani Hospital, Thailand [17]. While most deliveries (51.96\%) were normal, some $(39.21 \%)$ had caesarean delivery and some $(8.82$ $\%$ ) by vacuum. Out of 102 babies, presenting with Perinatal Asphyxia in children 57(55.88\%) were males and $45(44.11 \%)$ were females. This result is similar to the study done by Azam M in Multan [13]. Among the all 102 Perinatal Asphyxia in children case $30.39 \%$ were $<2500 \mathrm{gm}, 50 \%$ were between $2500-3500 \mathrm{gm}$ and $19.60 \%$ were $>3000 \mathrm{gm}$. Among the total 102 cases of Perinatal Asphyxia in children 16 (15.68\%) cases died. This result is similar with the result shown in one study done by Lodakhi G M in India [14]. Only 2(2.60\%) of HIE stageI, $5(33.33 \%)$ cases of HIE stage-II and 9 (90\%) cases of HIE stage-III died. Overall mortality in cases of Perinatal Asphyxia in children (15.6\%) was similar to the study done by S. J Etuk and I. S. Etak [21] in Nigeria where mortality rate was $14.3 \%$. The mortality rate in this study was quite high as compare to the study done in University of Calabar Teaching Hospital $(p<0.001)$. In this study mortality in HIE stageI and stage-II was quite similar with the study done by M.H Haidary [15] in Rajshahi, Bangaladesh but mortality in HIE stage-III was higher than other studies like M.H Haidary in Rajshahi where the mortality was only $60 \%$. The result regarding incidence of mortality in different stages of HIE was similar with one study done by Lodakhi GM in India [14]. This result was also higher than another study done by Mullign and Chawdhary where mortality due to severe Perinatal Asphyxia in children was $25.87 \%$. In this study recovery rate in HIE stage-I was $97.40 \%$, HIE stage-II was $66.66 \%$ and HIE stage-III was $10 \%$.

Limitations OF THE STUDY 
This was a prospective type of study with small number of sample size. So, the study result may not reflect the exact scenarios of the whole country.

\section{CONCLUSION AND \\ RECOMMENDATIONS}

Among all stages of Perinatal Asphyxia in children, HIE stage-II is the most common, then HIE stage-I and finally HIE stage-III. Babies with HIE Stage-III had a very poor prognosis whereas HIE stageI had a very good prognosis. Sepsis is the commonest morbidity in cases of Perinatal Asphyxia in children. Low birth weight and preterm babies more commonly suffered from Perinatal Asphyxia in children. Maternal gravida, pregnancy complication with PROM, meconium, APH, emergency caesarean section, preterm and male sex were the risk factors for Perinatal Asphyxia in children. Mortality and morbidity were more common in males than in females. Prospective and case control studies will be necessary in future to get more scientific ideas about Perinatal Asphyxia in children in the context of Bangladesh.

\section{REFERENCES}

1. World Health organization. Basic Newborn Resuscitation; A Practical Guide. World Health Organization: Geneva 1997 [Accessed February 27, 2007.2 Available: http:www.who.int/reproductive-

health/publication/MSM 98 /introductionen.html.

2. Lawn JE, Cousens S, Zupan J.4 million neonatal deaths: when? Where? Why? Lancet, 2005; 365:891-900.

3. Thornberg E, Thiringer K, Odeback A, Milson I. Perinatal Asphyxia in children; incidence, clinical course and outcome in a Swedish population. Acta Paediatr, 1995; 84:927-32.

4. Futrakul S, Praisawanna P, Thaitumyanon P. Risk factor for Hyposic- ischemic encephalopathy in asphyxiated newborn infant. Journal Med Assoc Thai, 2006; 89:322-8.

5. Chandre S, Ramji S, Thirupurum S, Perinatal asphyxia; multivariate analysis of risk factors in hospital birth. Indian Pediatr, 1997; 34:206-12.

6. Nelson KB, Ellenberg J. Apgar scores as preceptors of chronic neurological disability. Pediatrics, 1981; 68:36-44.

7. Ellis M, Manandhar DS, Manandhar N, Wyatt J, Balam AJ, Costello AM stillbirths and neonatal encephalopathy in kathmandu, Nepal: An estimate of the contribution of Perinatal Asphyxia in children to perinatal mortality in low income urban population. Paediatr Perinat Epidermiol, 2000;14:39-52.
8. Buchmann EJ, Pallinson RC, Myathikazi N.Intrapartum - related Perinatal Asphyxia in children in South Africa lessons from the first national perinatal care survey. S African Med Journal, 2002; 92:897-901.

9. Richard E. Behrman, Robert M. Kliegman, Editors. Hypoxia-Ischemia, Nelson text book of pediatric 17th ed. United States of America. Hal B Jenson; 2004:566-568.

10. Memon IA. Neonatal resuscitation. J Coll Physiol Surg Pak, 1995;5(4):163-164.

11. Dzadeyan E. Study on maternal mortality \& neonatal morbidity in Africa, Rural integrated Relief Service, Ghana 2007. http://www.who.int/pmnch/topics/health_system/ri rs_ghana/en/index.html. Downloaded on23/09/2010.

12. Daga AS, Daga SR, Patole SK. Risk assessment in Perinatal Asphyxia in children. Trop Pediatr, 1990; 36:34-39.

13. Azam M, Malik F, Khan P. Perinatal Asphyxia in children risk factors. The professional 2004; 11(4):416-423.

14. Ladakhi GM, Mubank M, Nabi B, Hassan M, Sethi AS. Neonatal risk factors and outcome of Perinatal Asphyxia in children. JK Practioner, 2000;7(4):267-70.

15. Haidary MH, Hussian A, Ahmed S, Kasem A. Clinical profile of Perinatal Asphyxia in children in Rajshahi medical college hospital. Journal Teachers Assoc, 2005;18:106-108.

16. Weal Hayel Khreisa, Zeiad Habahbeh, Risk factors of Perinatal Asphyxia in children: A study at Prince Ali Ben Al- Hussein Hospital Jod. Pak J Med Sci, 2005; 21(1):30-4.

17. Rachatapantanakorn $\mathrm{O}$, Tongkumchum $\mathrm{P}$, ChaisukantY, Factor associated with Perinatal Asphyxia in children in Pattani Hospital Thailand. Songkla Med J, 2005; 23(1):17-27.

18. Gomella TL, Cunning MD. Perinatal asphyxia. The Professional, 1999; 480-89.

19. Lee AC, Mullany LC, Tielsch JM, Katz J, Khatry SK, LeClerq SC, Adhikari RK, Shrestha SR, Darmstadt GL. Risk factors for neonatal mortality due to birth asphyxia in southern Nepal: a prospective, community-based cohort study. Pediatrics. 2008 May 1;121(5):e1381-90.

20. Lalsclottir K, Dagbjartsson A, Thorkellsson T, Hardottric H; Perinatal Asphyxia in children and hypoxic ischemic encephalopathy, incidence and obstetric risk factors. Laeknabladid, 2007; 93(9):595-60.

21. Etuk SJ, Etuk IS. Relative risk of Perinatal Asphyxia in children in babies of booked women who delivery nun-orthodox health facilities in Calabor, Nigeria. Acta Tropica, 2001; 79(2):143147. 